\title{
Validation Guidelines for a Jerky Pasteurization Process in a Low-Cost Dehydrator
}

\author{
Timothy J. Bowser* and Paul R. Weckler
}

Department of Biosystems and Agricultural Engineering, Oklahoma State University, Stillwater, USA

\begin{abstract}
Validation of a simple and inexpensive dehydration system used to achieve required lethality levels in jerky products is described. Factors influencing the dehydration process were investigated. Steps in the process can be used as validation guidelines for similar systems. Temperature variations within the drying chamber were reduced by improving air circulation and tuning the ventilation system with regard to fan speed, fan blade clearance and air flow path. The mechanical complexity of the system was simplified by replacing multiple, high-speed fans with a single, low-speed, highvolume fan. Wet-bulb temperature in the dehydration chamber was compared to the internal temperature of $6 \mathrm{~mm}$ thick marinated beef jerky slices during the pasteurization process. There was no significant difference between the dehydrator wet-bulb temperature and the product internal temperature after the wet-bulb temperature reached $60 \mathrm{C}$. Wet-bulb temperature can be used as an effective critical control point (CCP) for product pasteurization for specific cases when verified with field trials.
\end{abstract}

Keywords: Dehydrator, meat, jerky, validation, pasteurization.

\section{INTRODUCTION}

This paper describes the validation of a simple and inexpensive dehydration system that can be used to achieve required lethality levels in jerky products. In the validation process, guidelines for verifying similar systems are established. Bowser [1] describes the construction of a low-cost dehydrator that was developed for small-scale meat processors. The dehydrator was designed as an alternative to expensive commercial units that are out of the price range of many small meat processors and start-up companies. Bowser's publication provides a materials list, photographs, drawings and complete instructions necessary to build the dehydrator for a fraction of the cost of a commercial unit with similar capacity. The low-cost, simple dehydrator fills an equipment void that has long been empty. However, end users need more than equipment. Dehydration equipment must be proven to consistently produce a product that is wholesome and verifiably safe for human consumption.

In recent years, some dehydrated meats have received attention due to inadequate processing. Several outbreaks of gastroenteritis have been reported as a result of consuming beef jerky [2]. Acid adaptation of pathogens during the processing of beef jerky was studied by Calicioglu et al. [3]. Buege et al. [4] summarized the possible reasons behind the outbreaks when they reported that the traditional dehydration process for meats could result in an increased thermotolerance for bacteria [5] and evaporative cooling at the surface of the meat product [6]. The evaporative cooling could result in a reduced lethality of the drying process. A study by Faith et al. [7] indicated that percent fat content as well as time and temperature had an influence on E. coli $\mathrm{O} 157: \mathrm{H} 7$ inocu-

*Address correspondence to this author at the Department of Biosystems and Agricultural Engineering, Oklahoma State University, Stillwater, USA; E-mail: bowser@okstate.edu lated in beef jerky. Allen et al. [8] evaluated the effect of high humidity and wet marinade methods for pasteurization of jerky. They found that some marinade pasteurization methods were feasible, and may be a preferred alternative for small processors, since monitoring of dehydrator humidity was not necessary. It has been suggested by LaBudde [6] to process meat prior to dehydration with "wet heat" to achieve pasteurization. The USDA [9] published a compliance guideline for jerky processors. The guideline was intended "to provide small and very small meat and poultry plants with guidance material and updated information on the safe manufacture of jerky."

Guideline recommendations for thermal processing (or the lethality step) included maintaining a constant relative humidity above $90 \%$. Buege et al. [4] observed that the internal temperature of the product was always similar to the wet-bulb temperature during the early stages of the dehydration process. They followed this observation with a strong recommendation for processors to use wet-bulb temperature measurements to control thermal processes. The wet-bulb temperature may be the preferred process control metric, since it can be measured directly using a simple thermocouple, water reservoir and cotton wick. Proper maintenance of the wick and thermocouple calibration is required for ongoing operations. Measurement of relative humidity requires additional of more complex and expensive equipment compared to measurement of wet-bulb temperature.

As a practical consideration, humidity levels above $90 \%$ and high wet-bulb temperatures are difficult to achieve in drying chambers without the addition of steam. Any steam directly added to, or in contact with, a food product should be of the type that may be classified as "culinary" or "sanitary" steam [10]. Culinary steam is a utility that is often unavailable to the small and very small-scale meat processor because traditional steam generators (boilers) are relatively 
expensive. State and local codes may also require a license for boiler operation and periodic inspection by a designated official.

The Bowser dehydrator was designed to pasteurize product using high humidity. Required levels of humidity were achieved by evaporating water on the heating coil and by producing water vapor with a small, low-pressure electric water heater. The product pasteurization process required sealing the dehydrator by closing the inlet and outlet air ducts and entrance/exit door. Once the dehydrator was sealed, water vapor was added to the chamber along with heat through the forced-air heating coil. Pasteurization was completed when the target wet-bulb temperature was reached and held for the recommended time period [11]. Spot temperature measurements were taken at random locations in the dehydration chamber to check temperature consistency. Results revealed that the air temperature varied by as much as $10 \mathrm{C}$, which was regarded as unacceptable. This large temperature difference occurred at the product-loading end of the dehydration chamber from the top to bottom of the chamber during tests on the fully heated dehydrator at a temperature set point of $60 \mathrm{C}$. It was assumed that the wet-bulb temperature would vary proportionally with the dry-bulb temperature (verification of this assumption is given in the results section).

\section{MATERIALS AND METHODS}

Temperature variation within the Bowser dehydrator was believed by the authors to have been caused by poor air distribution which led to thermal gradients in the chamber. It was hypothesized that higher velocity, and more uniformly distributed air movement were needed to reduce temperature variations. Portable fans (model 1825 by Lasko Products, Inc., West Chester, PA) were purchased and placed in the dehydrator to test the hypothesis. Spot temperature measurements showed that the temperature variation was reduced significantly when the fans were used - confirming that increased air movement was needed. Since the portable fans were a temporary measure (they couldn't withstand the conditions of the high-humidity, high-temperature pasteurization process) they were replaced with six, $35.6 \mathrm{~cm}$ diameter, four blade fans (23 degree pitch, CCW rotation, MSC Supply, Melville, NY). The fan blades were mounted on shafts that extended through the wall of the dehydrator. Fan drives were externally mounted on the dehydrator where they were excluded from the high heat and humidity conditions of the drying chamber.

The shaft drive system consisted of two motors (model M3545, Baldor, Fort Smith, AR) and two variable-frequency drives (model L200, Hitachi America, Ltd., Tarrytown, NY) that were each linked to three fan shafts using a belt and four sheaves. This arrangement worked well to reduce temperature variations and provide independent control of fan banks, but was eventually abandoned because of fan balancing issues and high maintenance of the multiple fan blades, shafts, bearings and drives. A simpler method was needed to move air in the dehydrator. After some research, it was discovered that low speed, high volume fans (or LSHV fans) have been successfully used in similar applications. The advantages of LSHV fan system were immediately apparent: one motor, one belt, five drive shafts, six sheaves, and 10 bearings were eliminated from the previous system.
The installed fan (model 48-5-SLP-30-PAG-6WR-P1-1"BR, Multiwing America, Burton, $\mathrm{OH}$ ) is shown in Fig. (1). The LSHV fan shaft was located at the geometric center of the dehydration chamber on the end wall of the dehydrator. The location was selected to uniformly direct air over racks positioned in the dehydration chamber. A motor and variable-speed drive (described above), were used to power the LSHV fan. A $2.5 \mathrm{~cm}$ diameter by $61 \mathrm{~cm}$ long shaft with a full-length key and a flange bearing (mounted on the inside wall of the dehydrator) and pillow block bearing (mounted on the outside wall of the dehydrator) were used to support the LSHV fan.

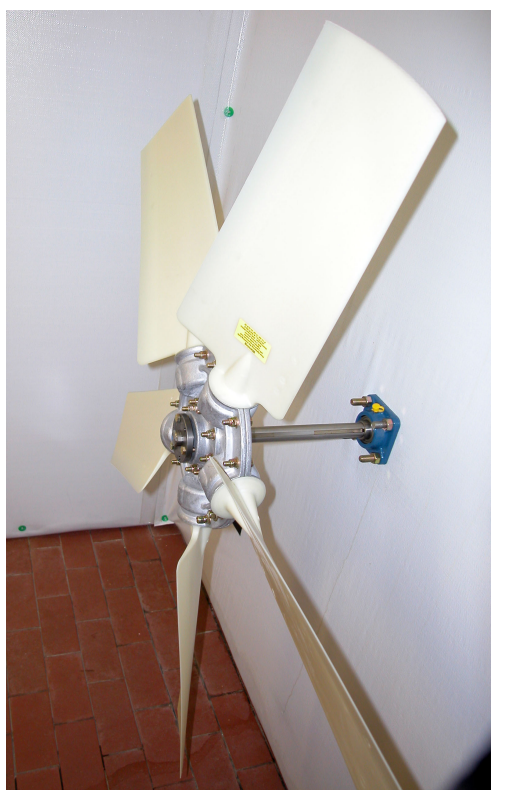

Fig. (1). Low-speed, high-volume fan used to improve air circulation in the dehydration chamber.

Distance (clearance) between the hub of the LSHV fan and the wall of the dehydrator was variable, based on the length of the shaft and the space available. Since the shaft was fully keyed, the LSHV fan could be positioned anywhere on its exposed length. This was important because, according to the manufacturer of the LSHV fan, clearance would affect air movement rates. An experiment was designed to determine the optimum clearance for the LSHV fan in the dehydrator. LSHV fan speed was fixed at $250 \mathrm{rpm}$ and the recirculation fan motor (which moved air past the heating coil of the dehydrator) was turned on at full speed. We started with $15 \mathrm{~cm}$ of clearance between the centerline of the LSHV fan hub and the dehydrator wall and measured the air speed at six locations around the perimeter of the dehydration chamber using a hot-wire anemometer (model 9545, TSI Inc., Shoreview, MN). The LSHV fan was moved away from the wall in $2 \mathrm{~cm}$ increments and air speeds recorded until the maximum available clearance of $31 \mathrm{~cm}$ was reached. It was assumed that the air speed would remain relatively constant at the optimum clearance distance.

Speed of the LSHV fan was adjustable using the variable-frequency drive. The maximum speed was determined to be $350 \mathrm{rpm}$, since at speeds above $400 \mathrm{rpm}$ vibrations were noticed in the LSHV fan system due to balancing and bearing and shaft alignment issues. An experiment was designed to determine the optimal speed of the LSHV fan (up 
to $400 \mathrm{rpm})$. We expected, based on the manufacturers input, that the air velocity inside the dehydration chamber would reach a peak at the optimum LSHV fan speed. During experiments, the recirculation fan was set at high speed. We adjusted the LSHV fan speed from 50 to $400 \mathrm{rpm}$ in increments of $50 \mathrm{rpm}$. Air velocity was measured using the same procedure given above.

We observed that recirculation air in the dehydrator was impinging on the dehydrator wall and the discharge side of the LSHV fan. To solve this, an adjustable baffle $(1.21 \mathrm{~mm}$ thick, $81 \times 56 \mathrm{~cm}$ galvanized flat sheet metal) was installed to help direct recirculated air to the low pressure side of the LSHV fan. Hinges were fixed to one of the long sides of the baffle and were anchored to the interior walls of the dehydrator. Anchoring points on the interior dehydrator walls were selected to allow full adjustment of the baffle angle, and to provide the most affect on the direction of the recirculated air. Three anchor locations were specified (shown in Fig. 2) and described below:

L1. Centered on the wall, directly across from and level with the bottom of the recirculated air discharge duct.

L2. Centered on the same wall as, and parallel with and adjacent to the top of the recirculated air discharge duct.

L3. Centered on the same wall as, and parallel with and adjacent to the bottom of the recirculated air discharge duct.

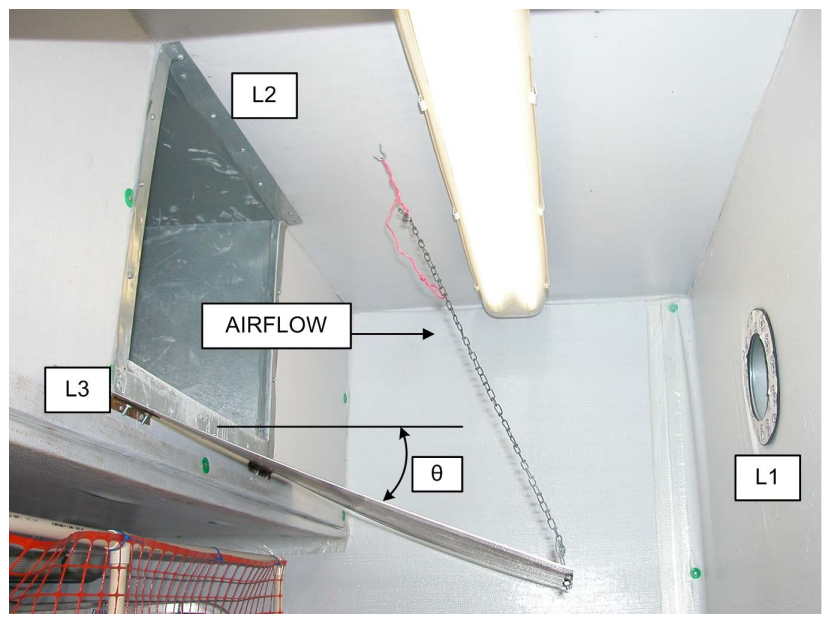

Fig. (2). Three anchor locations for the hinged baffle that were tested in the study. L1 is level with and directly opposite the bottom of the air duct discharge. L2 is parallel and adjacent to the top side of the air discharge duct. L3 (baffle position shown) is parallel and adjacent to the bottom side of the air duct. The baffle angle, $\theta$, was adjusted by changing the length of the anchor chain ( -15 degree baffle angle shown).

A small chain was attached to the side of the baffle opposite the hinges. The loose end of the chain was attached to a hook that was anchored on the dehydrator wall as shown in Fig. (2). The chain was used to adjust the angle of the baffle. In this paper, baffle angles refer to the angle that the body of the baffle makes with respect to the horizontal plane (see Fig. 2). Angles above the horizontal plane are positive, while angles below are negative.
The optimum baffle angle and location (anchor point) for our installation was determined by operating the dehydrator at a set temperature (about $60 \mathrm{C}$ ), without product and measuring the air temperature at 12 locations in the dehydrator. Optimum baffle angle and location would be identified when variation in temperature readings was minimized. The dehydrator was sealed and all racks and trays (no product) were placed in the dehydration chamber. The north wall of the dehydrator (Fig. 3) was drilled and two thermocouples (5TCTT-K-24-72, Omega Engineering, Stamford, CT) were inserted at each location (T1, T2, T3, T4, T5, and T6) marked in the figure. One thermocouple was placed just inside the north wall (and labeled T1N) at the location shown in Fig. (3); the other was placed at the same elevation directly across the dehydration chamber on the south wall (and labeled T1S). Each thermocouple was fixed at approximately $10 \mathrm{~cm}$ from the surface of the wall. All locations (T1 through T6) received two thermocouples that were placed similarly.

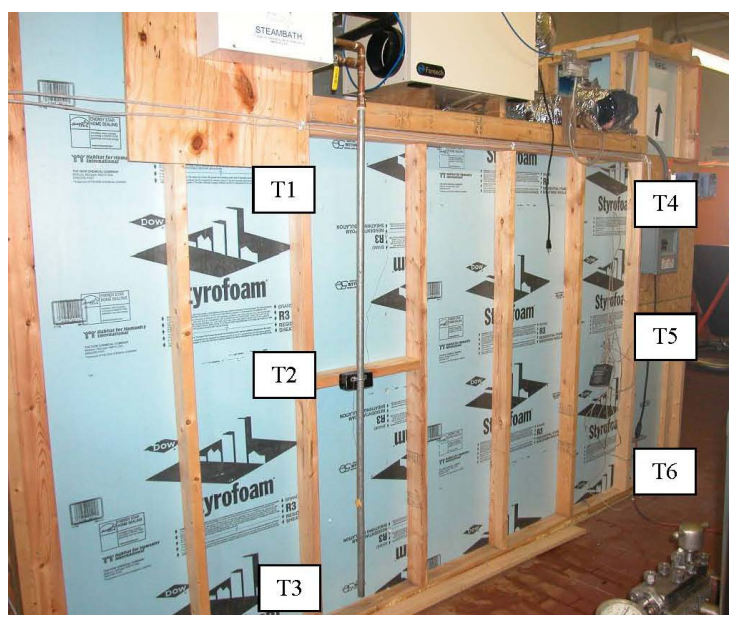

Fig. (3). North wall of dehydrator showing location of drilled holes where thermocouples where inserted to measure air temperature. Two thermocouples were inserted in each hole and placed on the north and south sides of the dehydration chamber.

Elevation (with respect to the floor of the dehydrator) of each thermocouple location was: $\mathrm{T} 1=\mathrm{T} 4=165 \mathrm{~cm}, \mathrm{~T} 2=\mathrm{T} 5=97$ $\mathrm{cm}$, and $\mathrm{T} 3=\mathrm{T} 6=20 \mathrm{~cm} . \mathrm{T} 1$ and $\mathrm{T} 4, \mathrm{~T} 2$ and $\mathrm{T} 5, \mathrm{~T} 3$ and $\mathrm{T} 6$, corresponded to the top shelf, middle shelf, and bottom shelf of a mobile drying rack, respectively. The temperature measurement locations were selected to account for as much variation in air flow as possible (prior tests revealed that most of the variation in temperature occurred near the walls of the chamber). A Fluke data logger (Hydra series II model 2635 A, Everett, WA) was used to record temperature data.

The baffle angle was adjusted in 15 degree increments, depending upon anchor location and freedom of movement available, and air temperature measurements were recorded when steady state conditions were reached. Baffle adjustment increments for each hinge location are listed in Table $\mathbf{1}$. Fan speed was fixed at $250 \mathrm{rpm}$ and fan clearance was 29 $\mathrm{cm}$.

After the optimum fan position, fan speed and baffle angle were determined, we verified the assumption that the wet-bulb temperature changed in direct proportion to the dry-bulb temperature. The 12 thermocouples described above were outfitted with $3.2 \mathrm{~mm}$ diameter water-wicking 
Table 1. Baffle Adjustment Increments for Each Hinge Location

\begin{tabular}{|c|c|c|c|}
\hline \multirow{2}{*}{ Angles Tested (degrees from horizontal } & \multicolumn{3}{|c|}{ Hinge Anchor Location (see Fig. 2) } \\
\cline { 2 - 4 } & L1 & L2 & X \\
\hline \hline 75 & $X$ & $X$ \\
\hline 60 & $X$ & $X$ \\
\hline 45 & $X$ & $X$ \\
\hline 30 & $X$ & $X$ \\
\hline 15 & $X$ & $X$ \\
\hline 0 & $X$ & $X$ & $X$ \\
\hline-15 & $X$ & $X$ & $X$ \\
\hline-30 & $X$ & $X$ & $X$ \\
\hline-45 & & $X$ & $X$ \\
\hline-60 & & $X$ & $X$ \\
\hline-75 & $X$ & $X$ \\
\hline
\end{tabular}

cotton sleeves (SKU \#4430, Pepperell Braiding Co., Pepperell, MA) to enable them to measure wet-bulb temperature. Location of the thermocouples did not change. The tip of each thermocouple was inserted about $1 \mathrm{~cm}$ into the end of a $1.0 \mathrm{~m}$ length of hollow cotton tube.

The free end of the cotton tube was kept in a water reservoir (237 ml capacity, item number 4293T77, McMaster Carr, Atlanta, GA) as shown in Fig. (4).

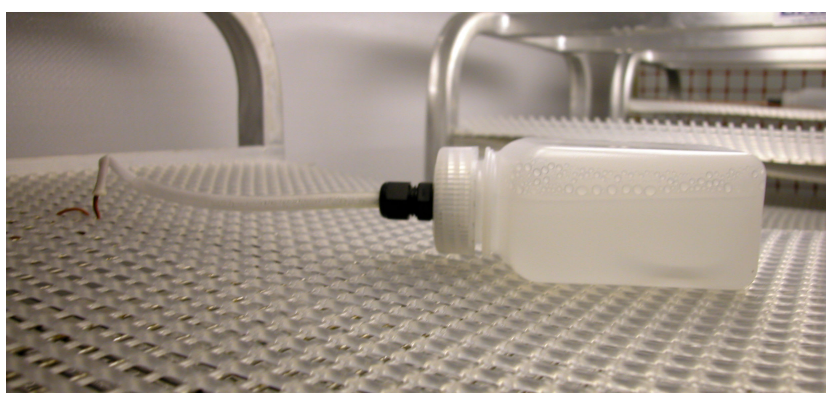

Fig. (4). Setup for wet-bulb temperature sensors showing the water reservoir and cotton sock placed over the thermocouple. A clear 10 $\mathrm{cm}$ long Tygon ${ }^{\circledR}$ tube covers the cotton wick from the reservoir to within about $2 \mathrm{~cm}$ of the terminus of the wick.

A $15 \mathrm{~cm}$ length of clear Tygon $\AA$ tubing $(6.35 \mathrm{~mm} \mathrm{OD}$, $0.80 \mathrm{~mm}$ wall thickness) was used to protect the wick between the point of exit from the water reservoir and the thermocouple. A Nylon liquid-tight cord grip (69915K47, McMaster Carr, Atlanta, GA) was threaded into the lid of the container and used to hold the Tygon ${ }^{\circledR}$ tubing in place.

The final validation test for the dehydrator was a comparison of the ambient wet-bulb temperature and internal temperature of beef jerky during the pasteurization process. The wet-bulb temperature was measured adjacent to four pieces of jerky using thermocouples and wet-bulb wicks as described. Internal temperature of the beef jerky was measured by carefully inserting a precision fine-wire thermocouple (Part \# 5TC-TT-K-30-72, Omega Engineering, Inc., Stamford, CT) into the center of meat slices before drying. Temperature data logging was accomplished using the Fluke
Hydra system as stated above. Meat slices were lean beef, approximately $6 \mathrm{~mm}$ thick, $8 \mathrm{~cm}$ wide and $25 \mathrm{~cm}$ long, marinated in a water-based flavoring solution prior to dehydration.

\section{RESULTS}

Results of the clearance test between the fan and the wall are plotted in Fig. (5). Optimal fan/wall clearance was obtained at $29 \mathrm{~cm}$ where the air velocity was nearly at the maximum and the standard deviation was relatively low. Fig. (6) gives a plot of average air speed in the dehydration chamber at various fan speed settings. The optimal fan speed was identified at $250 \mathrm{rpm}$ and was associated with peak air velocity in the dehydrator chamber. Plots of the standard deviation and range of air temperature measurements collected during tests for the optimum baffle angle and location are shown in Fig. (7). The baffle angles and location with the lowest standard deviation and range were between 0 and -30 degrees at baffle anchor location L3 (shown in Fig. 2). Wetbulb temperatures for the twelve measurement locations in the dehydrator averaged $53.5 \mathrm{C}$ over a time span of 1 minute $(\mathrm{n}=72)$ with a range of $0.816 \mathrm{C}$ and a standard deviation of $0.215 \mathrm{C}$

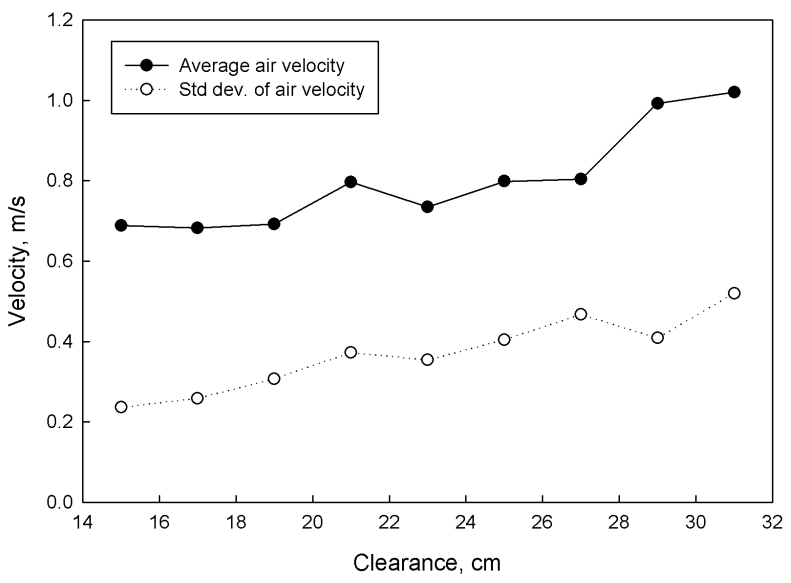

Fig. (5). Results of the test to determine optimum clearance between the fan hub and the dehydrator wall. 


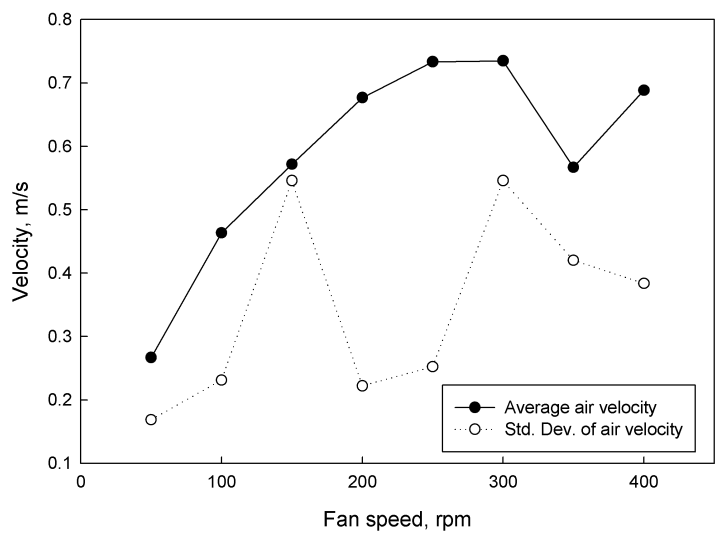

Fig. (6). Fan speed plotted against average air velocity (measured at six locations) downwind of the fan.

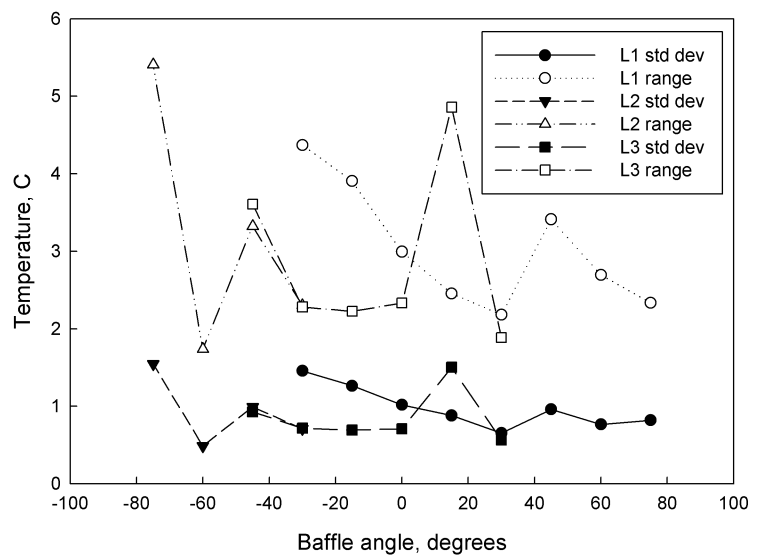

Fig. (7). Plot of range and standard deviation of air temperature measurements used to determine optimum baffle angle and location.

Fig. (8) shows a plot of average internal jerky temperature of the four slices of jerky and average wet-bulb temperature (taken adjacent to each jerky slice) vs. time in the dehydrator. Statistical analysis was performed on a portion of the data shown in the plot using Student's t-test to assess the difference between the measured wet-bulb temperature and the internal product temperature of the four slices of jerky

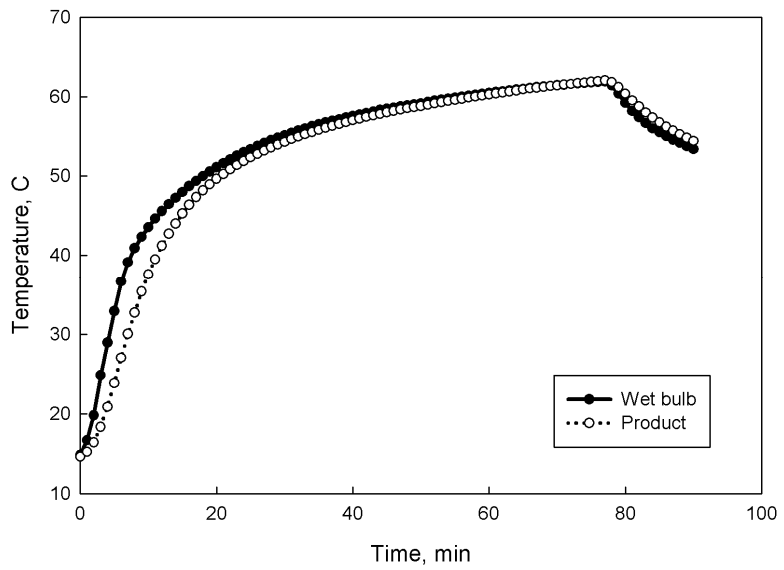

Fig. (8). Plot of internal jerky and wet-bulb temperature over time during the dehydrator start up and pasteurization process. for a 12-minute pasteurization process. Measurements taken during the warm up time prior to reaching the wet-bulb temperature set point $(60 \mathrm{C})$ for the pasteurization process were excluded from the data set to allow for startup conditions. Results of the t-test were calculated using Minitab v 14 (Minitab, Inc., State College, PA) and are shown in Table 2.

Table 2. Results of a paired t-test for dehydrator wet-bulb temperature and jerky slice internal temperature for a 12 minute pasteurization process (shown in figure 8), with wet-bulb temperature above $60 \mathrm{C}$. Number of observations $=48$

\begin{tabular}{|c|c|}
\hline Test & Result \\
\hline \hline $\begin{array}{c}\text { 99.9\% Confidence Interval for } \\
\text { mean difference }\end{array}$ & $(-0.2646,0.1908)$ \\
\hline T-value & -0.57 \\
\hline P-value & 0.572 \\
\hline
\end{tabular}

\section{DISCUSSION}

Temperature consistency (both dry and wet-bulb) throughout the dehydration chamber was an important factor that was used to tune the performance of the dehydrator. We found that uniform air flow and sufficient volume were vital for the maintenance of temperature consistency. Significant thermal gradients and air flow channels existed in the original dehydrator design that rendered the process unpredictable and unsafe (health risk from unpasteurized product). Improvements were needed to reduce temperature variation in the drying chamber. Fans were installed and tested to distribute air more uniformly within the drying chamber. A LSHV fan was found to provide the most adequate air movement without adding too much complexity to the system.

Three installation parameters were critical for optimum LSHV fan operation:

1. Fan clearance

2. Fan speed

3. Air flow

First, the fan should be mounted with adequate clearance between the low pressure side and its surroundings. We mounted the fan in a manner that allowed us to adjust the clearance between the inlet side of the fan and the adjacent wall of the dehydrator. Second, the fan should be operated at an optimum speed of rotation. Slower fan rotation may not achieve adequate mixing, while faster rotation wastes energy. An inexpensive, variable-frequency drive was purchased and installed to control the LSHV fans drive motor; providing a means for continuous speed adjustment within the manufacturer's recommended speed range.

Directing recirculation air flow to the fan was the third important parameter in optimizing the system performance. Return air to the LSHV fan was brought from the dehydration chamber in a separate duct and directed to the low pressure side of the fan using an adjustable baffle. The three baffle locations and various angles that were tested were deter- 
mined by visual estimation of the best flow path; then the optimum location and position were identified by experimentation.

Temperature consistency enhanced product safety since the process could achieve the critical control point (CCP) temperature with a higher degree of reliability. For example, if the CCP was a wet-bulb temperature of $60 \mathrm{C}$ for $12 \mathrm{~min}$ utes, and the process had a wet-bulb temperature standard deviation (sigma) of $0.22 \mathrm{C}$, then a six-sigma process would require a wet-bulb temperature set point of $60 \mathrm{C}+(0.22 \mathrm{C} \mathrm{x}$ $6)=61.32 \mathrm{C}$. The six-sigma process is statistically capable of producing fewer than two defects (products that did not achieve the pasteurization temperature) per million units produced [12]. Quality of the finished product would be enhanced because the wet-bulb temperature set point for pasteurization was increased by the relatively modest amount of $1.32 \mathrm{C}$ to achieve the six sigma production criterion. If the standard deviation of the wet-bulb temperature of the dehydrator had been $6 \mathrm{C}$, as it was before optimization, then the set point for the six sigma process would have been $60 \mathrm{C}+$ $(6 \mathrm{C} \times 6)=96 \mathrm{C}$. The $34.68 \mathrm{C}$ higher pasteurization temperature would require more energy to reach and could potentially reduce the overall quality of the product due to overcooking.

Based on the results of a paired t-test, we reject the hypothesis that there is a difference between the internal temperature of a jerky slice and the ambient wet-bulb temperature at a confidence level of $\mathrm{p}=0.572$. We are $99.9 \%$ confident that the wet-bulb temperature will be at most $0.19 \mathrm{C}$ higher and at least 0.26 lower than the internal temperature of the product. Practically this verifies the assumption that the ambient wet-bulb temperature of the dehydrator can be used as a CCP for the jerky pasteurization process with a 60 $\mathrm{C}$ set point using the given Bowser dehydration system. Below $60 \mathrm{C}$ the wet-bulb and internal jerky temperatures appear to be different, as shown in Fig. (8), and the wet-bulb temperature may not be a good estimate of the internal temperature of the product. Measurements of wet-bulb and product internal temperature should be recorded and compared for unique dehydrators and pasteurization processes to establish the validity of using the wet-bulb temperature as a CCP.

\section{ACKNOWLEDGEMENTS}

The authors acknowledge the receipt of a 2005 Cooperative Agreement Grant from the Food Safety and Inspection Services of the USDA that made this work possible. Dr. Kris Murthy, Senior Staff Officer, New Technology Staff, was responsible for overseeing the project for the USDA. Mr. Wayne Kiner, Shop Manager, and his capable staff of the Biosystems and Agricultural Engineering Department at Oklahoma State University, provided construction and shop services to build and modify the dehydrator. Dr. Roy Escoubas, Director, provided facilities and ongoing funding to operate the dehydrator at the Robert M. Kerr Food \& Agricultural Products Center at Oklahoma State University.

\section{REFERENCES}

[1] Bowser TJ. Construction and operation manual for: Low-cost, safe dehydrator for small and very small meat processors. 2007. Oklahoma State University, Food and Agricultural Products Center. Internet: http://fapc.okstate.edu/files/DehydratorManualV1.pdf (accessed April 18, 2008).

[2] Edison M, Sewell CM, Graves G, Olson R. Beef jerky gastroenteritis outbreaks. J Environ Health 2000; 62: 9-13.

[3] Calicioglu M, Sofos JN, Samelis J, Kendall PA, Smith GC. Destruction of acid- and non-adapted Listeria monocytogenes during drying and storage of beef jerky. Food Microbiol 2002; 19(6): 54559.

[4] Buege DR, Searls G, Ingham SC. Lethality of commercial wholemuscle beef jerky manufacturing process against Salmonella serovars and Escherichia coli O157:H7. J Food Prot 2005; 69(9): 2091-99

[5] Goepfert JM, Iskander IK, Amundson CH. Relation of the heat resistance of Salmonellae to the water activity of the environment. Appl Microbiol 1970; 19: 429-33.

[6] ProMED-mail. Salmonalla Kiambu, beef jerky - USA (New Mexico). Int Soc Infectious Diseases. Archive no. 20031001.2471. 2003. Internet: http://www.promedmail.org. (accessed August 29, 2007).

[7] Faith NG, Le Coutour NS, Alvarenga MB, Calicioglu M, Buege DR, Luchansky JB. Viability of E. coli $\mathrm{O} 157: \mathrm{H} 7$ in ground and formed beef jerky prepared at levels of 5 and $20 \%$ fat and dried at $52,57,63$, or 68 degree $\mathrm{C}$ in a home-style dehydrator. Int $\mathrm{J}$ Food Microbiol 1998; 41, 213-21.

[8] Allen K, Cornforth D, Whittier D, Vasavada M, Nummer B. Evaluation of High Humidity and Wet Marinade Methods for Pasteurization of Jerky, J Food Sci 2007; 72(7): C351-55.

[9] United States Department of Agriculture, Food Safety \& Inspection Service. Compliance guideline for meat and poultry jerky produced by small and very small plants. 2004. Internet: http://www.fsis. usda.gov/PDF/Compliance_Guideline_Jerky.pdf. (accessed August 29, 2007).

[10] Bowser TJ. Steam basics for food processors. Oklahoma State University Food and Agricultural Products Research and Technology Center, Stillwater, Oklahoma, 2006. Fact Sheet FAPC-142. Internet: http://fapc.okstate.edu/factsheets/fapc142.pdf. (accessed August 29, 2007).

[11] USDA FSIS. Appendix A of the "Compliance Guidelines for Meeting Lethality Performance Standards for Certain Meat and Poultry Products". 1999. Internet: http://www.fsis.usda.gov/oa/fr/95033Fa.htm; updated June, (accessed June 15, 2006).

[12] Joglekar AM. Statistical methods for six sigma in R\&D and manufacturing. New Jersey: John Wiley and Sons 2003. 